\title{
Developmental programming of energy balance and the metabolic syndrome
}

\author{
Elizabeth C. Cottrell and Susan E. Ozanne* \\ Department of Clinical Biochemistry, University of Cambridge, Addenbrooke's Hospital, Hills Road, \\ Cambridge CB2 2QR, UK
}

\begin{abstract}
The increasing prevalence of the metabolic syndrome in numerous populations throughout the world is currently of major concern, and presents a huge global health problem. The link between low birth weight and the subsequent development of obesity, disrupted glucose homeostasis and hypertension is now well established, and there is extensive evidence supporting these associations in both epidemiological and experimental studies. Alterations in the secretion of, and responses to, the circulating hormones insulin and leptin are likely candidates in terms of disease development. The aim of current research is to define how the central and peripheral pathways in which these signals exert their effects may be disrupted following poor early growth, and how this disruption contributes to the development of metabolic disease. The present review aims to outline the existing evidence whereby alterations in early growth may programme an individual to be at increased risk of the metabolic syndrome. The development of central appetite and expenditure circuits and of peripheral metabolic tissues, are likely to play a key role in the long-term regulation of energy balance.
\end{abstract}

Metabolic syndrome: Obesity: 'Thrifty phenotype': Leptin: Energy balance

The metabolic syndrome, a cluster of conditions including impaired glucose tolerance, dyslipidaemia and hypertension (Reaven, 1988), is becoming increasingly prevalent and contributes a major health burden in both developing and developed countries. Associations between fetal and early postnatal nutrition, patterns of growth and the subsequent development of obesity and other metabolic disorders have been shown in numerous epidemiological and clinical studies worldwide, and are supported by investigation in animal models (Hales et al. 1996). Developmental programming, whereby alterations in nutrition and growth imposed at critical periods during development result in long-term or permanent effects (Lucas, 1991), has gained much attention over recent years. In an ideal situation, strategies to provide optimal nutrition at crucial points during development would be the most beneficial in terms of minimising disease risk and reducing the substantial public health costs associated with these common metabolic diseases. To achieve these ends, clearly, there needs to be an understanding of the developmental processes involved, the roles played by nutrition and endocrine factors during this time and the 'normal' changes in responsiveness of different tissues throughout life.
Candidate targets for the programming of metabolic disease include central neuroendocrine circuits involved in the regulation of energy balance, as well as changes in peripheral tissue metabolism.

\section{Low birth weight and metabolic disease}

It has long been recognised that there is a relationship between impaired early growth and the subsequent development of adult disease. Early epidemiological studies established the association between poor fetal growth and increased risk of developing CVD (Barker \& Osmond, 1986), impaired glucose tolerance (Hales et al. 1991), and the metabolic syndrome (Barker et al. 1993). The 'thrifty phenotype hypothesis' put forward by Hales and Barker in 1992 (see Hales \& Barker, 2001), sought to explain why offspring exposed to poor prenatal nutrition are more susceptible to disease in later life. They proposed that in response to impaired nutrient supply (either as a result of maternal malnutrition or reduced placental function), the growing fetus will make adaptations in utero in order to maximise metabolic efficiency in relation to the storage 
and usage of fuels, to increase chances of survival postnatally. The programming of such a phenotype will continue to be beneficial if conditions of poor nutrition are extended into postnatal life; however, in the presence of adequate or plentiful nutrition these adaptations become detrimental and predispose to the development of obesity and associated features of the metabolic syndrome. Over the past two decades further epidemiological evidence and results from animal models have provided clear support for this hypothesis (Hales \& Barker, 2001).

A reduction in fetal nutrition usually results in a retardation of growth and organ-specific alterations in development, including the preservation of brain growth at the expense of other peripheral organs, such as the kidneys and pancreas (Desai et al. 1996). Results from experimental studies in animals have shown that in response to poor maternal nutrition there is a reduction in pancreatic cell mass (Snoeck et al. 1990) and in insulin secretory responses (Dahri et al. 1991). Alterations in kidney development, including a reduced number of nephrons and associated glomerular hypertrophy, are seen in low-birthweight subjects, and subsequently confer an increased risk of later renal failure (Zandi-Nejad et al. 2006). Changes in body composition, including an increase in adipose mass relative to lean mass, are also associated with low birth weight in man (Yajnik, 2000; Loos et al. 2001). As will be addressed, the combination of these factors contributes a much greater risk of developing the serious chronic diseases type 2 diabetes and CVD.

\section{Early growth, body composition and obesity development}

Impaired fetal growth, leading to a low birth weight, is associated with increased risk of obesity in childhood and later adult life (Ravelli et al. 1976; Gale et al. 2001; Kensara et al. 2005). In addition to increasing obesity risks, a low birth weight is associated with a tendency to store this excess adipose tissue centrally, which is an additional predictor of later metabolic disturbance (Yajnik, 2003; Bosy-Westphal et al. 2005). At the other end of the spectrum, overnutrition during fetal and early life is also associated with a detrimental disease profile in later life (Armitage et al. 2005). Both excessive maternal food intake and the consumption of a high-fat diet are associated with increased risks of CVD (Newman et al. 1986) and impaired glucose tolerance and diabetes development (McCance et al. 1994). Thus, the relationship between birth weight and metabolic disease is such that both those born small or large show increased risk of obesity in later life, leading to a ' $\mathrm{J}$ '- or ' $\mathrm{U}$ '-shaped relationship (Parsons et al. 2001).

Growth during pregnancy, and also during the early postnatal period, plays an important role in long-term health. Individuals who are born small but subsequently undergo catch-up growth during the early postnatal period have a higher extent of adiposity in later childhood and adult life, and increased insulin resistance (Leon et al. 1996; Forsen et al. 2000; Yajnik, 2000; Jaquet et al. 2005). In terms of glucose tolerance, reduced insulin sensitivity is predicted by increased weight gain during childhood (Yajnik, 2000; Ong \& Dunger, 2004). In a study of lowbirth-weight individuals the greatest extent of glucose intolerance was found to be present in those who were born small and were currently obese (Barker et al. 1993). The findings of these epidemiological studies have been confirmed using animal models, with low birth weight and subsequent development of obesity contributing independently and in an additive manner (Petry et al. 1997).

As well as alterations in fat mass, low-birth-weight individuals attain a lower lean muscle mass and strength and reduced bone density (Gale et al. 2001; Sayer \& Cooper, 2005). Given that muscle is the primary tissue involved in the uptake of glucose, a reduction in the amount of muscle mass would also predict a reduced glucose tolerance, leading to a more rapid or severe decline in metabolic control. In addition, it could also be predicted that a reduction in muscle mass itself would impact on an individual's ability to initiate exercise.

The maternal nutritional and endocrine environment, clearly, play a key role in the development of a growing fetus. Offspring of mothers with diabetes or impaired glucose tolerance, and who are therefore exposed to elevated levels of insulin, glucose and leptin, have increased risks of becoming obese (Plagemann et al. 2002; Catalano et al. 2003). In addition, infants of diabetic mothers who are fed breast milk from normoglycaemic women have a reduced risk of obesity in later childhood compared with those fed maternal milk (Plagemann et al. 2002). Breast-feeding itself has been found to lower obesity risk compared with formula feeding (Dewey, 2003). Postulated reasons for this association are the typically reduced energy intakes and growth rates associated with breast-fed infants (Heinig et al. 1993), and altered satiety responses or programmed differences in appetite regulation may also play a role.

Despite the abundant epidemiological evidence for the role of poor early growth predisposing to increased adipose accretion in later life, and its support in animal models, there is a relative paucity of information regarding the underlying mechanisms. There is clearly a need for further research in this area in order to determine the mechanisms involved in this response. In terms of programming effects contributing towards enhanced catch-up fat, it would be expected that in response to undernutrition in utero, adipocytes may have an enhanced ability to store fat. However, a recent study (Bieswal et al. 2004) has failed to find differences in either the proliferation or lipidaccumulating properties in vitro of adipocytes isolated from growth-retarded rats compared with controls. There is some evidence that offspring of protein-restricted dams show an increased hepatic expression of lipogenic enzymes (Maloney et al. 2003); however, whether permanent alterations in fuel partitioning may result following early developmental insult remains to be fully investigated.

\section{Regulation of catch-up growth}

Increasingly, the role of catch-up growth is receiving attention as being key in the development of metabolic disease. In addition, the fact that tissue-specific alterations 
occur is now providing some clues as to how the body responds to a period of deprivation to maximise fuel storage in case of repeated future nutritional restriction. Dulloo and colleagues (see Cettour-Rose et al. 2005, Dulloo, 2006) in a number of studies have shown that suppressed thermogenesis is a central process in catch-up growth. More specifically, it has been shown (Cettour-Rose et al. 2005) that during periods of re-feeding following semi-starvation, a state that induces suppression of thermogenesis in proportion to fat-store depletion, there is a redistribution of glucose such that skeletal muscle uptake is reduced while adipose tissue uptake is enhanced. Furthermore, adipose tissue fatty acid synthase activity is increased in these re-fed animals. Thus, it appears that coordinated alterations in tissue glucose handling confer a thrifty phenotype and that tissue-specific alterations in insulin sensitivity are involved. The way in which the body senses the reduction in adipose stores, and the signals and effector systems that mediate these responses, remain largely obscure (Dulloo, 2006).

\section{Hypothalamic regulation of energy balance}

In normal individuals the regulation of energy balance involves a matching of energy intake with expenditure in order to maintain a relatively stable body weight over an extended period of time. This process should be simple enough, yet in a modern Westernised society, with an overabundance of readily-available foods and an increasingly sedentary lifestyle, excess energy deposition, in the form of adipose tissue, challenges this regulation. When peripheral energy stores are sufficient circulating factors are released in proportion to these stores and they target key centres in the brain to coordinate a reduction in feeding, an increase in expenditure and a suppression of endogenous glucose production (Schwartz et al. 2000). Insulin was the first of such satiety signals to be identified. Following feeding, circulating insulin levels increase and insulin enters the brain via a regulated transport mechanism (Baura et al. 1993) where it acts to reduce energy intake and body weight (Woods et al. 1979). The second key hormone that has been shown to act as such a signal of plentiful fat stores is leptin, a peptide hormone that is secreted predominantly by adipocytes. In the adult circulating leptin levels are related to body mass (Maffei et al. 1995), but they are more closely correlated with the extent of adiposity (Liuzzi et al. 1999). Leptin, like insulin, is also transported across the blood-brain barrier by a saturable system (Banks et al. 1996).

Numerous early ablation studies (Schwartz et al. 2000) have indicated a key role for the hypothalamus in the regulation of energy balance. Within the hypothalamus the arcuate nucleus (ARC) is considered to be the initial site to receive input from circulating factors such as insulin and leptin. Two key populations of neurons in the ARC are involved in the 'first-order' sensing of energy stores. The first population express the orexigenic appetite-enhancing signals neuropeptide $\mathrm{Y}$ and agouti-related protein. The second population of neurons are those that express the anorexigenic pro-opiomelanocortin and cocaine- and amphetamine-regulated transcript neuropeptides. Centrally, an increase in insulin or leptin signalling acts to inhibit neuropeptide Y/agouti-related protein neurons of the ARC, while at the same time activating pro-opiomelanocortin/ cocaine- and amphetamine-regulated transcript cells, leading ultimately to a reduction in feeding and increase in energy expenditure (Schwartz et al. 2000). Conversely, in states of negative energy balance (such as starvation or fasting) leptin and insulin levels drop, feeding responses are increased and expenditure is reduced (Ahima, 2000). Thus, in addition to conveying information regarding whole-body adipose stores, a key role for leptin is in the signalling of more short-term changes in energy flux (Ahima \& Flier, 2000). Rapid changes in plasma leptin levels during fasting, in the absence of any change in total adipose tissue mass, are key in mediating the neuroendocrine adaptation to a fasting state (Ahima et al. 1996).

Appropriate peripheral secretion and central sensing of leptin and insulin have recently been recognised as key in the maintenance of body weight and glucose homeostasis (Schwartz \& Porte, 2005). As in peripheral tissues, hypothalamic insulin signalling involves the insulin receptor substrate-1-phosphatidylinositol 3-kinase pathway (Niswender et al. 2003). It is also now clear that leptin and insulin share a common signalling pathway at the level of the hypothalamus (Schwartz \& Niswender, 2004). Leptin receptor activation, which leads to the induction of suppressor of cytokine signalling-3 and prevents further signalling at the level of the receptor, also negatively influences insulin signalling (Ueki et al. 2004). In obese subjects both insulin and leptin levels are elevated (Liuzzi et al. 1999), but these individuals fail to respond appropriately. Central resistance to the anorectic and metabolic effects of these hormones is therefore thought to underlie many of the metabolic complications that arise during obesity. Interestingly, however, it appears that chronic hyperleptinaemia results in the development of selective leptin resistance. Although there is a loss of the appetite-suppressing and metabolism-enhancing effects of leptin, studies in rodents (Correia et al. 2002; Rahmouni et al. 2005) have shown that there is a preservation of the effects of this hormone on the cardiovascular system. The reasons for this disparity in leptin resistance are as yet unclear, but it provides a mechanism whereby obesity, with its associated hyperleptinaemic state, contributes to elevated blood pressure and associated cardiovascular complications.

In addition to central effects on appetite, leptin also plays a key role in the regulation of peripheral tissue metabolism. Leptin receptors are present in many nonneural tissues, and both direct and indirect (central nervous system-mediated) effects of leptin act to increase sympathetic nervous system activity (Haynes et al. 1997). As well as up regulating energy expenditure via central nervous system-mediated pathways, leptin acts to suppress lipogenesis and promote lipid oxidation (Minokoshi et al. 2002). This potent anti-steatotic role of leptin, opposing the fat-storing actions of insulin, is thought to be key in preventing ectopic deposition of lipid in non-adipose tissues (particularly muscle and pancreatic islets), and 
reducing lipotoxicity, a central process in the development of insulin resistance (Unger, 2003).

\section{Hypothalamic signalling: downstream of the arcuate nucleus}

Relatively less understood is the circuitry downstream of the ARC signalling, and the way in which a coordinated alteration in feeding and energy expenditure is achieved. The pro-opiomelanocortin/cocaine- and amphetamineregulated transcript and neuropeptide Y/agouti-related protein populations of the ARC, mentioned earlier, project to secondary sites within the hypothalamus, including the paraventricular nucleus, the lateral hypothalamic area, dorsal medial nucleus and the ventromedial nucleus. The melanocortin pathway is one efferent outflow that has received a large amount of attention in recent years, given its crucial role in the regulation of energy balance, both in human subjects and animal models. Indeed, in man genetic defects within the melanocortin pathway are the most common forms of monogenic obesity (O'Rahilly et al. 2003). The melanocortin peptides are derived from the cleavage of the pro-opiomelanocortin-precursor peptide, and they act through a family of receptors $(\mathrm{MC} 1-5 \mathrm{R})$ to inhibit food intake and increase energy expenditure (Cone, 2005). In terms of energy balance the MC4R subtype is considered to be most crucial, which is supported by the following findings: mutations in this receptor result in severe early-onset obesity in human subjects (Yeo et al. 1998); disruption of this gene results in hyperphagia and development of obesity in mice (Huszar et al. 1997); overexpression of the endogenous antagonist of the MC4R, agouti, also causes obesity (Klebig et al. 1995).

In terms of the downstream integration and possible divergence of appetite and expenditure regulation, a recent study (Balthasar et al. 2005) has shown that there is a divergence in the control of these systems downstream of the ARC. Using the obese MC4R-knock-out mouse model MC4R expression was reactivated specifically in hypothalamic sites thought to be critical in mediating the melanocortin actions. When MC4R was restored in paraventricular nucleus and amygdala neurons, a $60 \%$ reduction in the obesity associated with the MC4R-knockout phenotype was observed. Remarkably, this restoration was found to be associated with a correction of the hyperphagia in these animals, but had no effect on energy expenditure. Furthermore, there is now emerging evidence (Zhang \& Scarpace, 2006) that targetting of the melanocortin pathway, downstream of leptin actions, may provide a means of circumventing leptin resistance and therefore be of potential clinical relevance in the treatment of obesity.

\section{Leptin: a role in development of energy balance systems}

A critical role for leptin in the regulation of body weight is illustrated by the obese phenotype of the $o b / o b$ mouse model, which possesses a mutation in the leptin gene and is thus unable to secrete this hormone (Zhang et al. 1994).
Administration of leptin to these animals restores body weight to normal as a result of both a suppression of feeding and an increase in thermogenesis (Campfield et al. 1995; Halaas et al. 1995; Pelleymounter et al. 1995). Leptin administration to both mutant and wild-type animals promotes the mobilisation of fuels, produces an increase in $\mathrm{O}_{2}$ consumption and favours the expenditure of lipid as opposed to carbohydrate stores, as shown by a reduced RQ (Hwa et al. 1996).

In addition to these metabolic effects in the adult, investigation of an alternative role for leptin during the early postnatal period has been prompted by observations that $o b / o b$ mice show impaired central nervous system development, including reduced myelination and structural abnormalities within the hypothalamus (Bereiter \& Jeanrenaud, 1979, 1980; Sena et al. 1985). In addition, these mice fail to undergo normal reproductive maturation (Chehab et al. 1996), suggesting widespread impairments in the development of neuroendocrine systems. With this in mind, Ahima et al. (1998) sought to establish the ontogeny of leptin secretion during the early postnatal period in mice, and were able to show that there is a peak in circulating leptin levels during the early postnatal period, and that this rise does not correlate with body weight or body fat content.

In contrast to its effects in the adult rodent, during the early postnatal period leptin is unable to reduce food intake or increase energy expenditure (Mistry et al. 1999; Ahima \& Flier, 2000). Leptin receptor expression is present in the rodent ARC even during the embryonic period (Matsuda et al. 1999; Udagawa et al. 2000) and functional indications of leptin receptor signalling pathways are evident following exogenous leptin administration during the early postnatal period (Proulx et al. 2002; Bouret et al. 2004a). It has been proposed, therefore, that although the components of leptin signalling pathways are present and functional, they are not coupled to downstream regulatory pathways until later in development. Presumably, this state of leptin resistance is beneficial in order that neonatal animals maximise their nutritional intakes.

More recently, the work of Bouret and Simerly (Bouret et al. 2004a,b) has shown that the effects of leptin during the early postnatal period are indeed different from those in adulthood. Using the lipophilic tracer, DiI, an elegant series of studies (Bouret et al. 2004a) has demonstrated that in mice ARC axonal projections to downstream nuclei are immature at birth and subsequently develop during the first two postnatal weeks, and that distinct target nuclei are innervated at different stages. Furthermore, it was demonstrated (Bouret et al. 2004b) that ob/ob mice have a reduced innervation of these target nuclei, that neonatal but not adult leptin treatment can reverse these neuroanatomical defects and that leptin has a direct effect on stimulation of neurite outgrowth in hypothalamic explants from postnatal animals. Thus, these studies show distinct roles for leptin at different developmental stages (either neurotrophic during development or anorectic in adulthood; Fig. 1), and in addition show that there is a critical window of timing for the leptin-mediated development of hypothalamic energy balance circuits. 


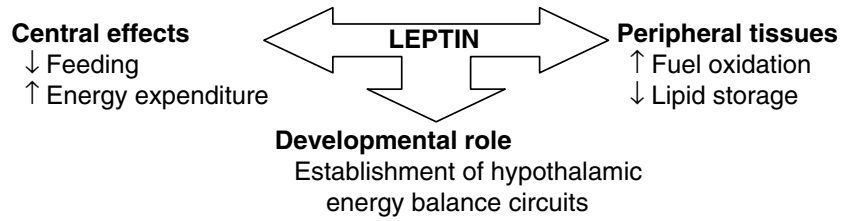

Fig. 1. Diverse roles of leptin in the regulation of energy balance. $\uparrow$, Increased; $\downarrow$, decreased.

\section{Early-life programming of appetite}

Evidence from animal models has shown that permanent changes in appetite pathways can result from alterations in nutrition during early life. Plagemann and coworkers (Plagemann et al. 1992, 1999; Davidowa \& Plagemann, 2001; Davidowa et al. 2003) have made extensive use of a rodent model in which litter size is reduced to three animals per dam for the duration of lactation in order to enhance food availability and therefore increase food intake and body-weight gain. These small-litter offspring have been shown reproducibly (Plagemann et al. 1992) to become hyperinsulinaemic in early postnatal life, to exhibit increased weight gain, adiposity and hyperphagia and to be more prone to diabetes in later life. Subsequent work using this model (Plagemann et al. 1999) has identified alterations in appetite regulatory pathways, at the level of the hypothalamus, as a result of this postnatal overfeeding. As well as these morphological changes, it has been shown (Davidowa \& Plagemann, 2001; Davidowa et al. 2003) that these animals are less responsive to the inhibitory effects of leptin and insulin, and thus the overall outcome is an enhanced orexigenic drive.

Subsequent to these findings, and of particular importance in terms of nutritional programming of appetite, it has been shown (Yura et al. 2005) that alterations in maternal and neonatal nutrition can alter the profile of the postnatal leptin surge and hypothalamic development. In mice, offspring of dams subjected to undernutrition during pregnancy exhibit a premature leptin surge, and subsequently go on to show an increased susceptibility to weight gain when weaned on to a high-fat diet. The importance of this premature spike as a causal factor in the later development of obesity has been demonstrated by artificially administering a premature leptin surge in normally-fed offspring, which results in the development of a phenotype indistinguishable from that of the undernourished offspring. Thus, it appears that the development of metabolic systems critically involves this postnatal leptin surge, and that this process can be greatly affected by early nutrition. In a rat model of maternal undernutrition it has again been shown (Vickers et al. 2005) that offspring go on to develop increased food intake and reduced energy expenditure, but remarkably that administration of leptin for $10 \mathrm{~d}$ during the neonatal period can correct this defect. The mechanisms in this case remain unclear. In another recent animal model it has been shown in rats (Desai et al. 2005) that maternal nutrient restriction and subsequent re-feeding during the lactational period results in a rapid catch-up growth during the early postnatal period, which is followed by a sustained elevated weight gain into adulthood. These animals have a lower birth weight and reduced levels of leptin at birth, but in later life attain a higher percentage body fat and became hyperleptinaemic. Together, the results of these animal studies suggest that early leptin levels provide cues that will affect the development of hypothalamic circuitry. It has yet to be determined if alterations in the postnatal leptin profile such as these have lasting effects on hypothalamic neuropeptide levels or programming of this central energy balance circuitry, but no doubt this issue will be the focus of research to come.

In human subjects there has been relatively little research into the ontogeny of early-life leptin levels. Maternal leptin levels are related to adiposity, and breast milk levels also reflect maternal fat mass (Houseknecht et al. 1997). Cord blood levels of leptin tend to reflect neonatal fat mass, and low cord leptin has been associated with rapid postnatal weight gain in small-for-gestationalage infants (Ong et al. 1999). As addressed previously, this catch-up growth is associated with an increased risk of later obesity and metabolic disease.

\section{Animal models}

Numerous animal models have now been established to study the mechanisms through which altered early nutrition and growth can affect the subsequent development of adult disease. Impaired early growth can be induced experimentally by means of maternal protein restriction (Hales et al. 1996; Langley-Evans, 1996; Lucas et al. 1996), energy restriction (Vickers et al. 2000), exposure to excess glucocorticoids (Seckl, 2004), maternal hypoxia (Williams et al. 2005), Fe restriction (Lewis et al. 2001; Gambling et al. 2003) and intrauterine artery ligation (Frampton et al. 1990; Simmons et al. 2001). In each of these models offspring are growth-retarded, have a lower birth weight and are more prone to disease in adulthood. In cases in which offspring are then subjected to enhanced or excessive nutrition postnatally (by the introduction of a high-fat or highly-palatable diet) the detrimental effects of this early growth restriction are augmented (Vickers et al. 2000; Ozanne et al. 2004a). Despite different means of inducing impaired growth, the similar phenotypic attributes (altered glucose homeostasis, increased fat deposition and development of hypertension) suggest that common pathways may be involved in the programming of metabolic disease in response to poor early growth. Although extrapolation of findings in animal models cannot be directly applied to the human situation, these models allow the investigation of mechanisms that might be of importance in the development of metabolic diseases.

Of these different models, the maternal low-protein condition is possibly the best characterised, and produces offspring with a phenotype very similar to that of the human metabolic syndrome (Desai et al. 1996; Ozanne et al. 1997; Ozanne et al. 2005). This model therefore represents a useful tool for the investigation of mechanisms that might underlie metabolic programming, and potentially for the determination of intervention strategies.

Within the authors' laboratory the low-protein intervention involves feeding either a standard control diet 


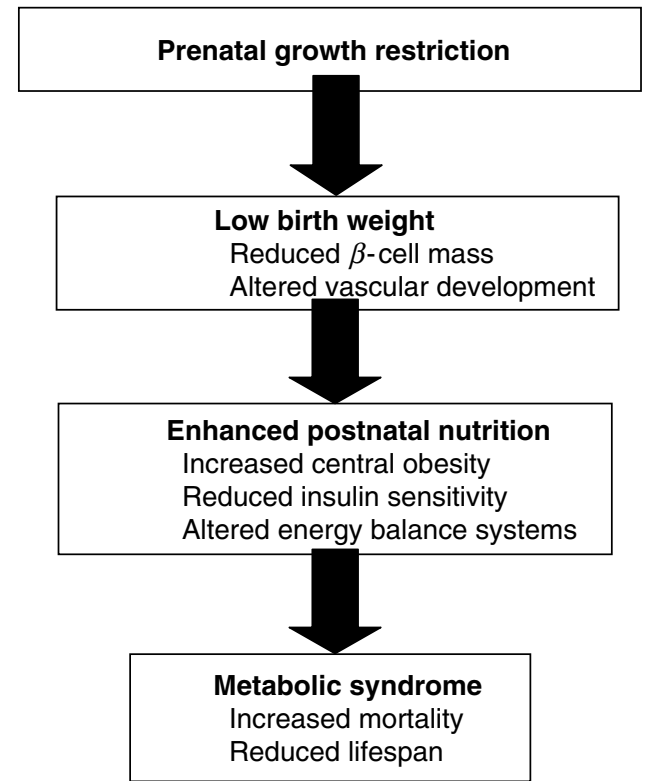

Fig. 2. Thrifty phenotype development of the metabolic syndrome.

containing $200 \mathrm{~g}$ protein $/ \mathrm{kg}$ or an isoenergetic diet having reduced protein $(80 \mathrm{~g} / \mathrm{kg})$ to female rodents during pregnancy and/or lactation. Growth restriction during gestation gives rise to offspring having a reduced body weight, and if the low-protein diet is continued throughout lactation these animals remain permanently smaller even when weaned onto a control diet (Desai et al. 1996; Ozanne et al. 1997, 2005). Initial studies have shown a wide range of programmed metabolic disturbances arising from these early-life dietary manipulations. In general, offspring of low-protein-fed dams show improved glucose-handling capabilities in early adult life, but undergo a greater agerelated decline in glucose tolerance, and have alterations in insulin-signalling pathways in muscle and adipose tissue (Hales et al. 1996; Ozanne et al. 1996, 1997).

In an extension of this low-protein protocol cross-over groups have been included to assess the differential effects of reduced growth at different stages of early development. The crossing of low-protein offspring to control-fed dams for the period of lactation ('recuperated' offspring) results in a rapid growth during this period, and conversely crossing control offspring to low-protein-fed females during lactation (postnatal low-protein animals) slows growth and permanently reduces body size (Hales et al. 1996; Ozanne et al. 2004a). One of the most striking findings of these studies is that rapid growth during lactation significantly reduces lifespan in male rats, whereas a slowing of growth during this period increases longevity (Hales et al. 1996). More recently, the low-protein crossover model has been applied in mice (Ozanne et al. 2004b), and again these findings on lifespan have been replicated. In addition, it has been shown that postnatal low-protein animals are resistant to weight gain when given access to a highly-palatable diet from weaning, suggesting changes in energy balance systems. In another animal model (Vickers et al. 2000) severe maternal energy restriction (to $30 \%$ control diet) results in the development of hyperphagia, obesity and hypertension in adult offspring, and additionally that these animals are hypometabolic. Furthermore, and in agreement with the authors' findings, these detrimental effects of impaired early growth are amplified in the presence of excessive postnatal nutrition (Vickers et al. 2003). Although the mechanisms underlying the phenotypic responses in this model remain to be defined, recent evidence suggests that a reduction in sensitivity to the appetite-reducing and metabolic effects of leptin may play an important role (Krechowec et al. 2006).

\section{Conclusions}

Impaired fetal growth is associated with increased risks of later metabolic disease, and these risks are amplified in the presence of accelerated growth during the early postnatal period and/or increased energy intake in later life (Fig. 2). Of importance in determining the ultimate outcome, the extent of disparity between early growth cues and subsequent level of nutrition are thought to be crucial (Gluckman et al. 2005). It appears that a lower plane of nutrition during the early postnatal period is protective in terms of later development of obesity and other metabolic complications. However, there is at present insufficient evidence to advocate a reduction in nutritional intake in human infants during the early life period as a means of reducing chronic disease, and clearly an intervention of this nature would be difficult to implement. Epigenetics, an expanding field investigating changes in gene expression as a result of alterations in DNA methylation and histone modifications, is receiving greater attention in terms of programming of the metabolic syndrome and other diseases (Gallou-Kabani \& Junien, 2005). There is a need for further investigation as to the way in which different organ systems develop in relation to altered growth trajectories and the mechanisms contributing to coordinated adaptations to nutrient supply. The relative contribution of changes in appetite pathways, body composition and metabolic rate are unclear at present. Future studies involving the low-protein model aim to further investigate these potential mechanisms, and it will also be of interest to determine the extent to which metabolic adaptations might remain plastic in later life. Ultimately, studies in this field will work toward the development of intervention strategies aimed at reducing the incidence of metabolic disease and alleviating the associated health and economic burdens.

\section{References}

Ahima RS (2000) Leptin and the neuroendocrinology of fasting. Frontiers of Hormone Research 26, 42-56.

Ahima RS \& Flier JS (2000) Leptin. Annual Review of Physio$\operatorname{logy}$ 62, 413-437.

Ahima RS, Prabakaran D \& Flier JS (1998) Postnatal leptin surge and regulation of circadian rhythm of leptin by feeding. Implications for energy homeostasis and neuroendocrine function. Journal of Clinical Investigation 101, 1020-1027.

Ahima RS, Prabakaran D, Mantzoros C, Qu D, Lowell B, Maratos-Flier E \& Flier JS (1996) Role of leptin in the neuroendocrine response to fasting. Nature 382, 250-252. 
Armitage JA, Taylor PD \& Poston L (2005) Experimental models of developmental programming: consequences of exposure to an energy rich diet during development. Journal of Physiology $565,3-8$

Balthasar N, Dalgaard LT, Lee CE, Yu J, Funahashi H, Williams $\mathrm{T}$ et al. (2005) Divergence of melanocortin pathways in the control of food intake and energy expenditure. Cell 123, 493-505.

Banks WA, Kastin AJ, Huang W, Jaspan JB \& Maness LM (1996) Leptin enters the brain by a saturable system independent of insulin. Peptides 17, 305-311.

Barker DJ, Hales CN, Fall CH, Osmond C, Phipps K \& Clark PM (1993) Type 2 (non-insulin-dependent) diabetes mellitus, hypertension and hyperlipidaemia (syndrome $\mathrm{X}$ ): relation to reduced fetal growth. Diabetologia 36, 62-67.

Barker DJ \& Osmond C (1986) Diet and coronary heart disease in England and Wales during and after the second world war. Journal of Epidemiology and Community Health 40, 37-44.

Baura GD, Foster DM, Porte D Jr, Kahn SE, Bergman RN, Cobelli C \& Schwartz MW (1993) Saturable transport of insulin from plasma into the central nervous system of dogs in vivo. A mechanism for regulated insulin delivery to the brain. Journal of Clinical Investigation 92, 1824-1830.

Bereiter DA \& Jeanrenaud B (1979) Altered neuroanatomical organization in the central nervous system of the genetically obese (ob/ob) mouse. Brain Research 165, 249-260.

Bereiter DA \& Jeanrenaud B (1980) Altered dendritic orientation of hypothalamic neurons from genetically obese (ob/ob) mice. Brain Research 202, 201-206.

Bieswal F, Hay SM, McKinnon C, Reusens B, Cuignet M, Rees WD \& Remacle C (2004) Prenatal protein restriction does not affect the proliferation and differentiation of rat preadipocytes. Journal of Nutrition 134, 1493-1499.

Bosy-Westphal A, Geisler C, Onur S, Korth O, Selberg O, Schrezenmeir J \& Muller MJ (2005) Value of body fat mass vs anthropometric obesity indices in the assessment of metabolic risk factors. International Journal of Obesity 30, 475-483.

Bouret SG, Draper SJ \& Simerly RB (2004a) Formation of projection pathways from the arcuate nucleus of the hypothalamus to hypothalamic regions implicated in the neural control of feeding behaviour in mice. Journal of Neuroscience 24, 2797-2805.

Bouret SG, Draper SJ \& Simerly RB (2004b) Trophic action of leptin on hypothalamic neurons that regulate feeding. Science 304, 108-110.

Campfield LA, Smith FJ, Guisez Y, Devos R \& Burn P (1995) Recombinant mouse OB protein: evidence for a peripheral signal linking adiposity and central neural networks. Science 269, 546-549.

Catalano PM, Kirwan JP, Haugel-de Mouzon S \& King J (2003) Gestational diabetes and insulin resistance: role in short- and long-term implications for mother and fetus. Journal of Nutrition 133, 1674S-1683S.

Cettour-Rose P, Samec S, Russell AP, Summermatter S, Mainieri D, Carrillo-Theander C, Montani JP, Seydoux J, RohnerJeanrenaud F \& Dulloo AG (2005) Redistribution of glucose from skeletal muscle to adipose tissue during catch-up fat: a link between catch-up growth and later metabolic syndrome. Diabetes 54, 751-756.

Chehab FF, Lim ME \& Lu R (1996) Correction of the sterility defect in homozygous obese female mice by treatment with the human recombinant leptin. Nature Genetics 12, 318-320.

Cone RD (2005) Anatomy and regulation of the central melanocortin system. Nature Neuroscience 8, 571-578.

Correia ML, Haynes WG, Rahmouni K, Morgan DA, Sivitz WI \& Mark AL (2002) The concept of selective leptin resistance: evidence from agouti yellow obese mice. Diabetes 51, 439-442.

Dahri S, Snoeck A, Reusens-Billen B, Remacle C \& Hoet JJ (1991) Islet function in offspring of mothers on low-protein diet during gestation. Diabetes 40, 115-120.

Davidowa H, Li Y \& Plagemann A (2003) Altered responses to orexigenic (AgRP, MCH) and anorexigenic $(\alpha-\mathrm{MSH}, \mathrm{CART})$ neuropeptides of paraventricular hypothalamic neurons in early postnatally overfed rats. European Journal of Neuroscience 18, 613-621.

Davidowa H \& Plagemann A (2001) Inhibition by insulin of hypothalamic VMN neurons in rats overweight due to postnatal overfeeding. Neuroreport 12, 3201-3204.

Desai M, Crowther NJ, Lucas A \& Hales CN (1996) Organselective growth in the offspring of protein-restricted mothers. British Journal of Nutrition 76, 591-603.

Desai M, Gayle D, Babu J \& Ross MG (2005) Programmed obesity in intrauterine growth-restricted newborns: modulation by newborn nutrition. American Journal of Physiology 288, R91-R96.

Dewey KG (2003) Is breastfeeding protective against child obesity? Journal of Human Lactation 19, 9-18.

Dulloo AG (2006) Regulation of fat storage via suppressed thermogenesis: a thrifty phenotype that predisposes individuals with catch-up growth to insulin resistance and obesity. Hormone Research 65, Suppl. 3, 90-97.

Forsen T, Eriksson J, Tuomilehto J, Reunanen A, Osmond C \& Barker D (2000) The fetal and childhood growth of persons who develop type 2 diabetes. Annals of Internal Medicine 133, 176-182.

Frampton RJ, Jonas HA, MacMahon RA \& Larkins RG (1990) Failure of IGF-1 to affect protein turnover in muscle from growth-retarded neonatal rats. Journal of Developmental Physiology 13, 125-133.

Gale CR, Martyn CN, Kellingray S, Eastell R \& Cooper C (2001) Intrauterine programming of adult body composition. Journal of Clinical Endocrinology and Metabolism 86, 267-272.

Gallou-Kabani C \& Junien C (2005) Nutritional epigenomics of metabolic syndrome: new perspective against the epidemic. Diabetes 54, 1899-1906.

Gambling L, Dunford S, Wallace DI, Zuur G, Solanky N, Kaila S, Srai S \& McArdle HJ (2003) Iron deficiency during pregnancy affects postnatal blood pressure in the rat. Journal of Physiology 552, 603-610.

Gluckman PD, Hanson MA, Morton SM \& Pinal CS (2005) Life-long echoes - a critical analysis of the developmental origins of adult disease model. Biology of the Neonate 87, 127-139.

Halaas JL, Gajiwala KS, Maffei M, Cohen SL, Chait BT, Rabinowitz D, Lallone RL, Burley SK \& Friedman JM (1995) Weight-reducing effects of the plasma protein encoded by the obese gene. Science 269, 543-546.

Hales CN \& Barker DJ (2001) The thrifty phenotype hypothesis. British Medical Bulletin 60, 5-20.

Hales CN, Barker DJ, Clark PM, Cox LJ, Fall C, Osmond C $\&$ Winter PD (1991) Fetal and infant growth and impaired glucose tolerance at age 64. British Medical Journal 303, 1019-1022.

Hales CN, Desai M, Ozanne SE \& Crowther NJ (1996) Fishing in the stream of diabetes: from measuring insulin to the control of fetal organogenesis. Biochemical Society Transactions 24, 341-350.

Haynes WG, Sivitz WI, Morgan DA, Walsh SA \& Mark AL (1997) Sympathetic and cardiorenal actions of leptin. Hypertension 30, 619-623.

Heinig MJ, Nommsen LA, Peerson JM, Lonnerdal B \& Dewey KG (1993) Energy and protein intakes of breast-fed and 
formula-fed infants during the first year of life and their association with growth velocity: the DARLING Study. American Journal of Clinical Nutrition 58, 152-161.

Houseknecht KL, McGuire MK, Portocarrero CP, McGuire MA \& Beerman K (1997) Leptin is present in human milk and is related to maternal plasma leptin concentration and adiposity. Biochemical and Biophysical Research Communications 240, 742-747.

Huszar D, Lynch CA, Fairchild-Huntress V, Dunmore JH, Fang Q, Berkemeier LR et al. (1997) Targeted disruption of the melanocortin-4 receptor results in obesity in mice. Cell $\mathbf{8 8}$, 131-141.

Hwa JJ, Ghibaudi L, Compton D, Fawzi AB \& Strader CD (1996) Intracerebroventricular injection of leptin increases thermogenesis and mobilizes fat metabolism in ob/ob mice. Hormone and Metabolic Research 28, 659-663.

Jaquet D, Deghmoun S, Chevenne D, Collin D, Czernichow P \& Levy-Marchal C (2005) Dynamic change in adiposity from fetal to postnatal life is involved in the metabolic syndrome associated with reduced fetal growth. Diabetologia $\mathbf{4 8}$, 849-855.

Kensara OA, Wootton SA, Phillips DI, Patel M, Jackson AA \& Elia M (2005) Fetal programming of body composition: relation between birth weight and body composition measured with dual-energy X-ray absorptiometry and anthropometric methods in older Englishmen. American Journal of Clinical Nutrition 82, 980-987.

Klebig ML, Wilkinson JE, Geisler JG \& Woychik RP (1995) Ectopic expression of the agouti gene in transgenic mice causes obesity, features of type II diabetes, and yellow fur. Proceedings of the National Academy of Sciences USA 92, 4728-4732.

Krechowec SO, Vickers M, Gertler A \& Breier BH (2006) Prenatal influences on leptin sensitivity and susceptibility to dietinduced obesity. Journal of Endocrinology 189, 355-363.

Langley-Evans SC (1996) Intrauterine programming of hypertension in the rat: nutrient interactions. Comparative Biochemistry and Physiology 114A, 327-333.

Leon DA, Koupilova I, Lithell HO, Berglund L, Mohsen R, Vagero D, Lithell UB \& McKeigue PM (1996) Failure to realise growth potential in utero and adult obesity in relation to blood pressure in 50 year old Swedish men. British Medical Journal 312, 401-406.

Lewis RM, Petry CJ, Ozanne SE \& Hales CN (2001) Effects of maternal iron restriction in the rat on blood pressure, glucose tolerance, and serum lipids in the 3-month-old offspring. Metabolism 50, 562-567.

Liuzzi A, Savia G, Tagliaferri M, Lucantoni R, Berselli ME, Petroni ML, De Medici C \& Viberti GC (1999) Serum leptin concentration in moderate and severe obesity: relationship with clinical, anthropometric and metabolic factors. International Journal of Obesity and Related Metabolic Disorders 23, 1066-1073.

Loos RJ, Fagard R, Beunen G, Derom C \& Vlietinck R (2001) Birth weight and blood pressure in young adults: a prospective twin study. Circulation 104, 1633-1638.

Lucas A (1991) Programming by early nutrition in man. Ciba Foundation Symposium 156, 38-50.

Lucas A, Baker BA, Desai M \& Hales CN (1996) Nutrition in pregnant or lactating rats programs lipid metabolism in the offspring. British Journal of Nutrition 76, 605-612.

McCance DR, Pettitt DJ, Hanson RL, Jacobsson LT, Bennett PH \& Knowler WC (1994) Glucose, insulin concentrations and obesity in childhood and adolescence as predictors of NIDDM. Diabetologia 37, 617-623.

Maffei M, Halaas J, Ravussin E, Pratley RE, Lee GH, Zhang Y et al. (1995) Leptin levels in human and rodent: measurement of plasma leptin and ob RNA in obese and weight-reduced subjects. Nature Medicine 1, 1155-1161.

Maloney CA, Gosby AK, Phuyal JL, Denyer GS, Bryson JM \& Caterson ID (2003) Site-specific changes in the expression of fat-partitioning genes in weanling rats exposed to a lowprotein diet in utero. Obesity Research 11, 461-468.

Matsuda J, Yokota I, Tsuruo Y, Murakami T, Ishimura K, Shima K \& Kuroda Y (1999) Development changes in long-form leptin receptor expression and localization in rat brain. Endocrinology 140, 5233-5238.

Minokoshi Y, Kim YB, Peroni OD, Fryer LG, Muller C, Carling D \& Kahn BB (2002) Leptin stimulates fatty-acid oxidation by activating AMP-activated protein kinase. Nature $\mathbf{4 1 5}$, 339-343.

Mistry AM, Swick A \& Romsos DR (1999) Leptin alters metabolic rates before acquisition of its anorectic effect in developing neonatal mice. American Journal of Physiology 277, R742-R747.

Newman WP 3rd, Freedman DS, Voors AW, Gard PD, Srinivasan SR, Cresanta JL, Williamson GD, Webber LS \& Berenson GS (1986) Relation of serum lipoprotein levels and systolic blood pressure to early atherosclerosis. The Bogalusa Heart Study. New England Journal of Medicine 314, 138-144.

Niswender KD, Morrison CD, Clegg DJ, Olson R, Baskin DG, Myers MG Jr, Seeley RJ \& Schwartz MW (2003) Insulin activation of phosphatidylinositol 3-kinase in the hypothalamic arcuate nucleus: a key mediator of insulin-induced anorexia. Diabetes 52, 227-231.

Ong KK, Ahmed ML, Sherriff A, Woods KA, Watts A, Golding J \& Dunger DB (1999) Cord blood leptin is associated with size at birth and predicts infancy weight gain in humans. ALSPAC Study Team. Avon Longitudinal Study of Pregnancy and Childhood. Journal of Clinical Endocrinology and Metabolism 84, 1145-1148.

Ong KK \& Dunger DB (2004) Birth weight, infant growth and insulin resistance. European Journal of Endocrinology 151, Suppl. 3, U131-U139.

O'Rahilly S, Farooqi IS, Yeo GS \& Challis BG (2003) Minireview: human obesity - lessons from monogenic disorders. Endocrinology 144, 3757-3764.

Ozanne SE, Fernandez-Twinn D \& Hales CN (2004a) Fetal growth and adult diseases. Seminars in Perinatology 28, 81-87.

Ozanne SE, Jensen CB, Tingey KJ, Storgaard H, Madsbad S \& Vaag AA (2005) Low birthweight is associated with specific changes in muscle insulin-signalling protein expression. Diabetologia 48, 547-552.

Ozanne SE, Lewis R, Jennings BJ \& Hales CN (2004b) Early programming of weight gain in mice prevents the induction of obesity by a highly palatable diet. Clinical Science 106, 141-145.

Ozanne SE, Nave BT, Wang CL, Shepherd PR, Prins J \& Smith GD (1997) Poor fetal nutrition causes long-term changes in expression of insulin signaling components in adipocytes. American Journal of Physiology 273, E46-E51.

Ozanne SE, Wang CL, Coleman N \& Smith GD (1996) Altered muscle insulin sensitivity in the male offspring of proteinmalnourished rats. American Journal of Physiology 271, E1128-E1134.

Parsons TJ, Power C \& Manor O (2001) Fetal and early life growth and body mass index from birth to early adulthood in 1958 British cohort: longitudinal study. British Medical Journal 323, 1331-1335.

Pelleymounter MA, Cullen MJ, Baker MB, Hecht R, Winters D, Boone T \& Collins F (1995) Effects of the obese gene product on body weight regulation in ob/ob mice. Science $\mathbf{2 6 9}$, $540-543$ 
Petry CJ, Ozanne SE, Wang CL \& Hales CN (1997) Early protein restriction and obesity independently induce hypertension in 1-year-old rats. Clinical Science 93, 147-152.

Plagemann A, Harder T, Franke K \& Kohlhoff R (2002) Longterm impact of neonatal breast-feeding on body weight and glucose tolerance in children of diabetic mothers. Diabetes Care 25, 16-22.

Plagemann A, Harder T, Rake A, Voits M, Fink H, Rohde W \& Dorner G (1999) Perinatal elevation of hypothalamic insulin, acquired malformation of hypothalamic galaninergic neurons, and syndrome x-like alterations in adulthood of neonatally overfed rats. Brain Research 836, 146-155.

Plagemann A, Heidrich I, Gotz F, Rohde W \& Dorner G (1992) Obesity and enhanced diabetes and cardiovascular risk in adult rats due to early postnatal overfeeding. Experimental and Clinical Endocrinology 99, 154-158.

Proulx K, Richard D \& Walker CD (2002) Leptin regulates appetite-related neuropeptides in the hypothalamus of developing rats without affecting food intake. Endocrinology 143, 4683-4692.

Rahmouni K, Correia ML, Haynes WG \& Mark AL (2005) Obesity-associated hypertension: new insights into mechanisms. Hypertension 45, 9-14.

Ravelli GP, Stein ZA \& Susser MW (1976) Obesity in young men after famine exposure in utero and early infancy. New England Journal of Medicine 295, 349-353.

Reaven GM (1988) Banting lecture 1988. Role of insulin resistance in human disease. Diabetes 37, 1595-1607.

Sayer AA \& Cooper C (2005) Fetal programming of body composition and musculoskeletal development. Early Human Development 81, 735-744.

Schwartz MW \& Niswender KD (2004) Adiposity signaling and biological defense against weight gain: absence of protection or central hormone resistance? Journal of Clinical Endocrinology and Metabolism 89, 5889-5897.

Schwartz MW \& Porte D Jr (2005) Diabetes, obesity, and the brain. Science 307, 375-379.

Schwartz MW, Woods SC, Porte D Jr, Seeley RJ \& Baskin DG (2000) Central nervous system control of food intake. Nature 404, 661-671.

Seckl JR (2004) Prenatal glucocorticoids and long-term programming. European Journal of Endocrinology 151, U49U62.

Sena A, Sarlieve LL \& Rebel G (1985) Brain myelin of genetically obese mice. Journal of the Neurological Sciences $\mathbf{6 8}$, 233-243.

Simmons RA, Templeton LJ \& Gertz SJ (2001) Intrauterine growth retardation leads to the development of type 2 diabetes in the rat. Diabetes 50, 2279-2286.

Snoeck A, Remacle C, Reusens B \& Hoet JJ (1990) Effect of a low protein diet during pregnancy on the fetal rat endocrine pancreas. Biology of the Neonate 57, 107-118.

Udagawa J, Hatta T, Naora H \& Otani H (2000) Expression of the long form of leptin receptor (Ob-Rb) mRNA in the brain of mouse embryos and newborn mice. Brain Research $\mathbf{8 6 8}$, 251-258.

Ueki K, Kondo T, Tseng YH \& Kahn CR (2004) Central role of suppressors of cytokine signaling proteins in hepatic steatosis, insulin resistance, and the metabolic syndrome in the mouse. Proceedings of the National Academy of Sciences USA 101, 10422-10427.

Unger RH (2003) Minireview: weapons of lean body mass destruction: the role of ectopic lipids in the metabolic syndrome. Endocrinology 144, 5159-5165.

Vickers MH, Breier BH, Cutfield WS, Hofman PL \& Gluckman PD (2000) Fetal origins of hyperphagia, obesity, and hypertension and postnatal amplification by hypercaloric nutrition. American Journal of Physiology 279, E83-E87.

Vickers MH, Breier BH, McCarthy D \& Gluckman PD (2003) Sedentary behavior during postnatal life is determined by the prenatal environment and exacerbated by postnatal hypercaloric nutrition. American Journal of Physiology 285, R271-R273.

Vickers MH, Gluckman PD, Coveny AH, Hofman PL, Cutfield WS, Gertler A, Breier BH \& Harris M (2005) Neonatal leptin treatment reverses developmental programming. Endocrinology 146, 4211-4216.

Williams SJ, Campbell ME, McMillen IC \& Davidge ST (2005) Differential effects of maternal hypoxia or nutrient restriction on carotid and femoral vascular function in neonatal rats. American Journal of Physiology 288, R360-R367.

Woods SC, Lotter EC, McKay LD \& Porte D Jr (1979) Chronic intracerebroventricular infusion of insulin reduces food intake and body weight of baboons. Nature 282, 503-505.

Yajnik C (2000) Interactions of perturbations in intrauterine growth and growth during childhood on the risk of adult-onset disease. Proceedings of the Nutrition Society 59, 257-265.

Yajnik CS (2003) Nutrition, growth, and body size in relation to insulin resistance and type 2 diabetes. Current Diabetes Reports 3, 108-114.

Yeo GS, Farooqi IS, Aminian S, Halsall DJ, Stanhope RG \& O'Rahilly S (1998) A frameshift mutation in MC4R associated with dominantly inherited human obesity. Nature Genetics $\mathbf{2 0}$, 111-112.

Yura S, Itoh H, Sagawa N, Yamamoto H, Masuzaki H, Nakao K, Kawamura M, Takemura M, Kakui K, Ogawa Y \& Fujii S (2005) Role of premature leptin surge in obesity resulting from intrauterine undernutrition. Cell Metabolism 1, 371-378

Zandi-Nejad K, Luyckx VA \& Brenner BM (2006) Adult hypertension and kidney disease: the role of fetal programming. Hypertension 47, 502-508.

Zhang Y, Proenca R, Maffei M, Barone M, Leopold L \& Friedman JM (1994) Positional cloning of the mouse obese gene and its human homologue. Nature 372, 425-432.

Zhang Y \& Scarpace PJ (2006) Circumventing central leptin resistance: lessons from central leptin and POMC gene delivery. Peptides 27, 350-364. 